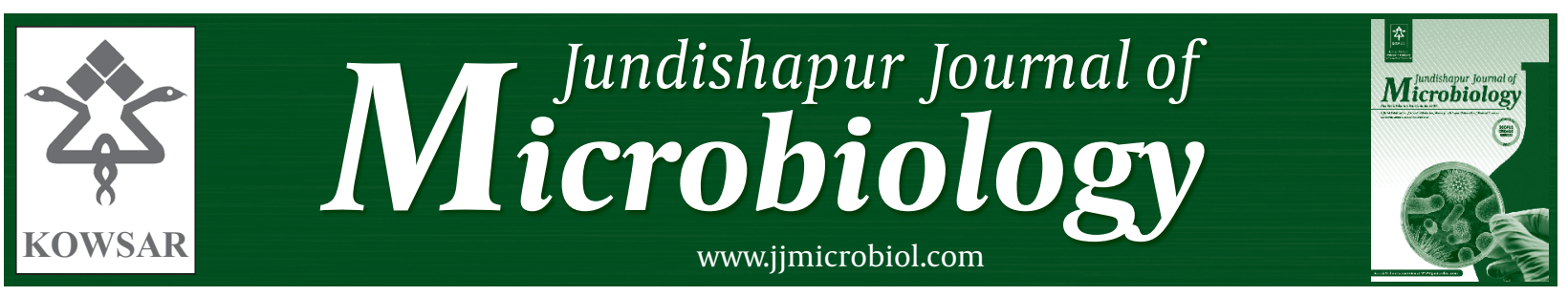

\title{
Relative Frequency of Rotavirus and Adenovirus Among Children Aged 1-60 Months Hospitalized With Acute Diarrhoea in South-Western, Iran
}

\author{
Tahereh Ziaei Kajbaf ${ }^{{ }^{*}}$, Ahmad Shamsizadeh ${ }^{2}$, Gholamreza Kalvandi ${ }^{3}$, Manoochehr \\ Macvandi ${ }^{4}$ \\ ${ }^{1}$ Department of Pediatrics, Ahvaz Jundishapur University of Medical Sciences, Ahvaz, IR Iran \\ ${ }^{2}$ Department of Pediatric infectious diseases, Ahvaz Jundishapur University of Medical Sciences, Ahvaz, IR Iran \\ ${ }^{3}$ Department of Pediatrics, Ilam University of Medical Sciences, Ilam, IR Iran \\ ${ }^{4}$ Department of Medical Microbiology, School of Medicine and Infectious and Tropical Disease Research Center, Ahvaz Jundishapur University of Medical \\ Science, Ahvaz, IR Iran
}

\begin{tabular}{l}
\hline A R T I C L E I N F O \\
\hline Article type: \\
Original Article \\
\hline
\end{tabular}

Article history:

Received: 10 Jan 2012

Revised: 12 Mar 2012

Accepted: 29 Apr 2012

\section{Keywords:}

Acute Diarrhoea

Rotavirus

Adenovirus

Children

Ahvaz

\begin{abstract}
A B S T R A C T
Background: More than three million children in developing countries die from acute diarrhea annually. Rotaviruses and Adenoviruses are from the most important etiologic factors in acute gastroenteritis of children.

Objectives: The aim of this study was to determine the prevalence of rotavirus and adenovirus among children with acute diarrhoea admitted to Abuzar Hospital in Ahvaz (Southwest Iran).

Patients and Methods: In a descriptive, cross-sectional study over 1 year (September 2009 to August 2010), children who were admitted to Abuzar Hospital in Ahvaz with a diagnosis of acute diarrhoea were studied. Stools were examined with ELISA kits for detection of adenoviruses and rotaviruses.

Results: Of 180 children in our study, 104 were boys (57.8\%) and 76 were girls (42.2\%), with a mean age of 12.86 months (1-60 months). Sixty-three (35\%) had rotavirus infections (mean age, 11.57 months), and 6 (3.3\%) had adenovirus infections (mean age, 8.17 months). We examined the seasonal distribution and found that 12 cases (19\%) had occurred in spring, 11 (17.5\%) in summer, 24 (38.1\%) in autumn, and 16 (25.4\%) in winter. There was no significant correlation between sex and viral agents causing acute diarrhoea $(P=0.96)$. Conclusions: This survey showed a high incidence of rotavirus infection (35\%) in children with acute diarrhoea, especially in children under 2 years old. It seems that use of an appropriate vaccine could effectively prevent diarrhoea in this population.
\end{abstract}

Published by Kowsar Corp, 2013. cc 3.0.

Implication for health policy/practice/research/medical education:

This study has highlighted the need to vaccination against rotavirus in Iranian population to reduce the prevalence of acute diarrhoea.

- Please cite this paper as:

Ziaei Kajbaf T, Shamsizadeh A, Kalvandi G, Macvandi M. Relative Frequency of Rotavirus and Adenovirus Among Children Aged 1-60 Months Hospitalized With Acute Diarrhoea in South-Western, Iran.Jundishapur J Microbiol. 2013;6(1):47-50. DOI: 10.5812/jjm.4072

\footnotetext{
${ }^{*}$ Corresponding author: Tahereh Ziaei Kajbaf, Pediatric Department, Abuzar Children's Hospital, Ahvaz Jundishapour University of Medical Sciences, Ahvaz, IR Iran. Tel:+98-9166030525, Fax:+98-6114433715, E-mail: ziaei42@yahoo.co.uk

DOI: $10.5812 / j j \mathrm{jm} .4072$

(C) 2013 Ahvaz Jundishapur University of Medical Sciences; Published by Kowsar Corp

This is an Open Access article distributed under the terms of the Creative Commons Attribution License (http://creativecommons.org/licenses/by/3.0), which permits unrestricted use, distribution, and reproduction in any medium, provided the original work is properly cited.
} 


\section{Background}

Acute infectious diarrhoea is a common disease in young children throughout the world. The mortality rate has been estimated to be 1.6-2.5 million cases per year, the majority of which occur in developing countries (1).

Rotavirus is the most important cause of severe dehydrating diarrhoea in early childhood (2). In developed countries, rotaviruses are detected in $35-50 \%$ of children hospitalized with acute diarrhoea $(3,4)$. Enteric adenot viruses are ubiquitous. They are considered the primary cause of epidemic diarrhoea and onset of diarrhoeal disease in hospitals and day-care centres $(5,6)$. The rate of enteric adenoviruses varies from $1-8 \%$ in developed countries $(7,8)$ to $2-31 \%$ in developing countries (9-11).

\section{Objectives}

Considering the high prevalence of gastroenteritis in our region and absence of regional epidemiological data on aforementioned viruses, we performed this study to determine the relative frequency of rotavirus and adenovirus in children hospitalized with acute gastroenteritis in Abuzar Hospital at Ahvaz, in southwest Iran. Epidemiological aspects such as sex, age, and season were assessed.

\section{Patients and Methods}

This descriptive epidemiological study was carried out in Ahvaz, southwest Iran, from September 2009 to August 2010. The study population included children aged 1-60 months who were admitted to Abuzar Hospital with a diagnosis of acute diarrhoea. Acute diarrhoea was defined as 3 or more occurrences of watery or loose stool daily, lasting for 3 to 13 days (12). All subjects were selected by simple random sampling. The collect tion of fecal samples was carried out in the first $24 \mathrm{~h}$ of hospitalization, after written informed consent was obtained from parents or legal guardians. Patients with negative $\mathrm{RBC}$ and $\mathrm{WBC}$ in their stool examination and no evidence of food poisoning were included. Children with a previous history of immunosuppressive therapy or documented significant background diseases such as immunodeficiency syndromes were excluded. Only 1 fresh stool sample was collected per child. The faecal specimens were obtained at the time of admission and transferred to the virology laboratory, where the samples were stored at $-70^{\circ} \mathrm{C}$.

Sample size was calculated as $\frac{Z^{2} P(1-P)}{d^{2}}$, where $d=0.07, z=$ 1.96 , and $P=0.3$ (according to the other studies) [8,12] , and the specimens were tested for the presence of rotaviral and adenoviral antigens by ELISA(ELISA kit: Diaplus, Inc., North York, Ontario, Canada). The assay was performed according to manufacturer's instructions. The sensitivity and specificity of ELISA test for faecal specimens has been established previously (13). Patients' demographic data including age, sex, type of nutrition (breast-fed vs. formula-fed) were recorded.

Statistical analysis of the collected data was performed with SPSS v.13 software. The differences in proportions were compared using the Chi-square test and a P value less than 0.05 was considered statistically significant.

\section{Results}

Of 180 children with acute gastroenteritis admitted to the hospital, 104 (57.8\%) were male and 76 (42.2\%) were female. Rotavirus was detected in the faeces of 63 (35\%) patients and adenovirus in 6 (3.3\%). The frequency of diarrhoea was significantly higher in males $(P=0.044)$. Fisher's t-test showed no significant relationship between gender and type of diarrhoeal virus $(P=0.21)$. The mean age of patients with acute diarrhoea was $12.86 \pm 13.02$ months (range, 1-60 months). The highest prevalence was observed in 7-12 months children (37.2\%). The distribution according to age is shown in Figure 1.

In rotavirus-infected group, the mean age was $11.57 \pm$ 9.21 months (range, 2-48 months). In adenovirus-infected group, the mean age was $8.17 \pm 4$ months (range, 2-14

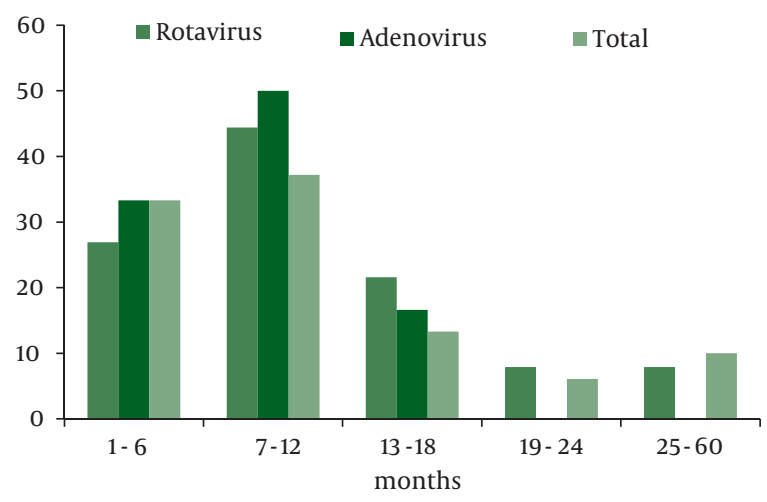

Figure1. Distribution of Infections Caused by Adenovirus and Rotavirus, by Age.

months) (Figure 1).

Rotavirus was detected throughout the year. The prevalence of rotavirus gastroenteritis was 19\% in spring, 17.5\% in summer, $38.1 \%$ in autumn, and $25.4 \%$ in winter (Figure 2 ). Accordingly, the relative frequency of rotavirus gastroenteritis was highest in autumn. Adenovirus-infected group $(n=6)$ had 4 patients in spring $(66.7 \%)$, no patients in summer, 1 in autumn (16.7\%), and 1 in winter (16.7\%). A significant difference was observed between incidence of rotavirus in cold season and rest of the year, as demonstrated by the Chi-square test $(P=0.012)$. Sixty-five $(36.1 \%)$ patients were exclusively breast-fed, 69 (38.3\%) were formula-fed, 29 (16.1\%) patients were fed with both formula and breast milk, and 17 (9.4\%) were on a family diet. There was no significant difference between the type of feeding and prevalence of diarrhoea $(P>0.05)$. 


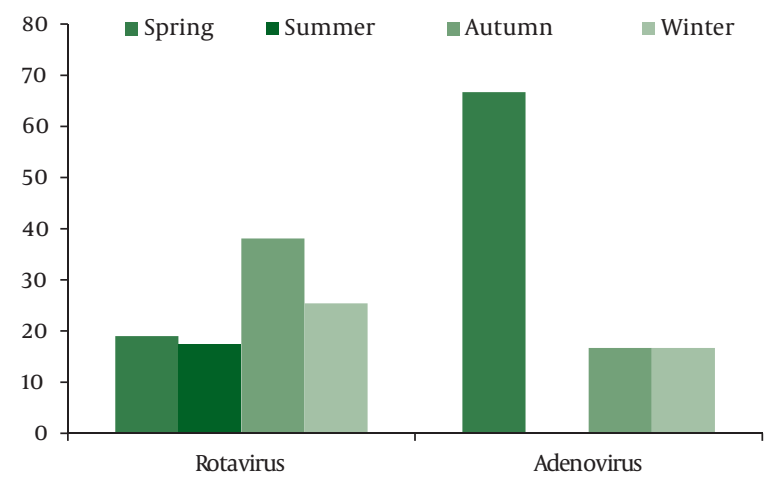

Figure 2. Seasonal Distribution of Infections Caused by Adenovirus and Rotavirus

\section{Discussion}

Acute gastroenteritis is one of the most common causes of admission to health centres, and viral diarrhoea is a major cause of morbidity and mortality in developing countries $(1,14)$. This study showed that rotaviruses are important aetiological agents of acute gastroenteritis in children less than 5 years of age in Ahvaz (35\%), accounting for one-third of all cases with acute diarrhoea. A similar prevalence (30.8\%) was obtained in a study performed in Iran (15). Our results reinforced the previous finding that rotavirus is responsible for $20-60 \%$ of severe diarrhoeal illnesses requiring hospitalization of children in developed and developing countries (4, 15-17). Lower prevalence ( $9 \%$ ) also has been reported from Nigeria and Gaborone $(3,18)$.

The prevalence of adenovirus infection in this study was $3.3 \%$, much lower than the rates reported in north-western Nigeria (22.3\%) (19). A similar prevalence (3.3\%) was obtained in studies in Korea and Brazil $(20,21)$ and in a study performed in another city of Iran, Babul (2.9\%) (22). A lower prevalence of 1.5\% was reported in Argentina (23). Such divergence may be observed due to epidemiological condition of the virus in regions with different climates or be attributed to study design. Our study population was consisted of 180 children with acute diarrhoea, of which 104 were male (57.7\%) and 76 (42.2\%) were female; according to our results, the prevalence of acute diarrhoea was higher in males than in females $(P=0.04)$, but no significant relationship between gender and causative virus was observed $(P=0.96)$. This result is similar to other studies performed in Iran $(22,24)$.

In our study, $92 \%$ of the patients positive for rotavirus were under 2 years of age, with the highest prevalence between 7-12 months (44.4\%). This age distribution is comparable to previous reports $(22,24)$. The low rate of rotavirus disease in infants under 7 months of age has been attributed to a higher rate of breast feeding in this age group, providing partial protection due to presence of maternal antibodies in the breast milk.

Rotavirus cases were more common between the months of October and March. The highest prevalence was seen in autumn (38.1\%) and winter (25.4\%). In studies carried out in our country, rotavirus cases are more frequently seen in winter $(12,22)$,but in another study, the detection rate was highest in spring (25). In the Asian ros tavirus surveillance study, rotavirus cases were observed with higher frequency between December and March in northern regions, but a seasonal increase was not observed in countries with tropical climates (26). In similar studies in the U.S (14), the highest prevalence was in wint ter, but in the Busu study in South Africa (9), the highest prevalence of rotavirus was in autumn and winter, which is consistent with our results. Geographical location seems to be important for determining the seasonal variability of rotavirus-related gastroenteritis. The seasonal distribution of adenovirus gastroenteritis showed a greater prevalence of infection in spring (66.7\%). Unfortunately, the number of cases was too small to draw any significant conclusion about the seasonality or other epidemiological data of adenovirus infection.

In our study, $38.3 \%$ of the children were formula-fed and $36.1 \%$ were breast-fed with no significant difference $(P>$ $0.05)$, a result that is not consistent with another study performed in Iran, in which formula-fed infants were more frequently afflicted with diarrhoeal diseases (12). Few reports are available on epidemiology of viral gastroenteritis in various parts of Iran. Further investigations are needed to provide more accurate data on the epidemiology and serotypes of rotaviruses and other viral agents causing acute diarrhoea in this country.

As limitation, because ELISA method vs. PCR (polymerase chain reaction) could result in a false positive result, over estimation in our study is a possibility. This study showed a high prevalence of rotavirus infection in patients less than 2 years of age with acute diarrhoea (35\%); it seems rational to use rotavirus vaccine in this population in our region to reduce prevalence of acute diarrhoea.

\section{Acknowledgements}

This study was supported by the research deputy of Jundishapur University of Medical Sciences. The authors would like to thank Mr. Charaghian for his help in statistical analysis of the results.

\section{Financial Disclosure}

None declared.

\section{Funding/Support}

This study was supported by the research deputy of Jundishapur University of Medical Sciences.

\section{Authors' Contribution}

None declared. 


\section{References}

1. Kosek M, Bern C, Guerrant RL. The global burden of diarrhoeal disease, as estimated from studies published between 1992 and 2000. Bull World Health Organ. 2003;81(3):197-204.

2. Parashar UD, Gibson CJ, Bresee JS, Glass RI. Rotavirus and severe childhood diarrhea. Emerg Infect Dis. 2006;12(2):304-6.

3. Barnes GL, Uren E, Stevens KB, Bishop RF. Etiology of acute gastroenteritis in hospitalized children in Melbourne, Australia, from April 1980 to March 1993. J Clin Microbiol.1998;36(1):133-8.

4. Payne DC, Staat MA, Edwards KM, Szilagyi PG, Gentsch JR, Stockman LJ, et al. Active, population-based surveillance for severe rotavirus gastroenteritis in children in the United States. Pediatrics. 2008;122(6):1235-43.

5. Carraturo A, Catalani V, Tega L. Microbiological and epidemiological aspects of rotavirus and enteric adenovirus infections in hospitalized children in Italy. New Microbiol. 2008;31(3):329-36.

6. Lew JF, Moe CL, Monroe SS, Allen JR, Harrison BM, Forrester BD, et al. Astrovirus and adenovirus associated with diarrhea in children in day care settings. J Infect Dis. 1991;164(4):673-8.

7. Bon F, Fascia P, Dauvergne M, Tenenbaum D, Planson H, Petion AM, et al. Prevalence of group A rotavirus, human calicivirus, astrovirus, and adenovirus type 40 and 41 infections among children with acute gastroenteritis in Dijon, France. J Clin Microbiol. 1999;37(9):3055-8.

8. Grimwood K, Carzino R, Barnes GL, Bishop RF. Patients with enteric adenovirus gastroenteritis admitted to an Australian pediatric teaching hospital from 1981 to 1992. J Clin Microbiol. 1995;33(1):131-6.

9. Basu G, Rossouw J, Sebunya TK, Gashe BA, de Beer M, Dewar JB, et al. Prevalence of rotavirus, adenovirus and astrovirus infection in young children with gastroenteritis in Gaborone, Botswana. East Afr Med J. 2003;80(12):652-5.

10. Cruz JR, Caceres P, Cano F, Flores J, Bartlett A, Torun B. Adenovirus types 40 and 41 and rotaviruses associated with diarrhea in children from Guatemala. J Clin Microbiol.1990;28(8):1780-4.

11. Herrmann JE, Blacklow NR, Perron-Henry DM, Clements E, Taylor DN, Echeverria P. Incidence of enteric adenoviruses among children in Thailand and the significance of these viruses in gastroenteritis. J Clin Microbiol. 1988;26(9):1783-6.

12. Kazemi A, Tabatabaie F, Agha-Ghazvini MR, Kelishadi R. The Role of rotavirus in acute pediatric diarrhea in Isfahan, Iran. PakJ Med Sci. 2006;22(3):282-5.

13. Cicek C, Karatas T, Altuglu I, Koturoglu G, Kurugol Z, Bilgic A. Comparison of ELISA with shell vial cell culture method for the detection of human rotavirus in fecal specimens. New Microbiol. 2007;30(2):113-8.
14. Charles MD, Holman RC, Curns AT, Parashar UD, Glass RI, Bresee JS. Hospitalizations associated with rotavirus gastroenteritis in the United States, 1993-2002. Pediatr Infect Dis J. 2006;25(6):48993.

15. Meqdam M, Shdaifat A, Malkawi H. Prevalence and characteristics of rotavirus group A causing gastroenteritis in Northern Jordan. Singapore Paediatr J. 2001;43(1):10-7.

16. Akan H, Izbirak G, Gurol Y, Sarikaya S, Gunduz TS, Yilmaz G, et al. Rotavirus and adenovirus frequency among patients with acute gastroenteritis and their relationship to clinical parameters: a retrospective study in Turkey. Asia Pac Fam Med. 2009;8(1):8.

17. Vainio K, Nordbo SA, Njolstad G, Storvold G, Dollner H, Midgaard $C$, et al. Detection and characterization of group A rotaviruses in children hospitalized with acute gastroenteritis in Norway, 2006-2008. J Med Virol. 2009;81(10):1839-44.

18. Aminu M, Esona MD, Geyer A, Steele AD. Epidemiology of rotavirus and astrovirus infections in children in northwestern Nigeria. Ann Afr Med. 2008;7(4):168-74.

19. Aminu M, Ahmad AA, Umoh JU, de Beer MC, Esona MD, Steele AD. Adenovirus infection in children with diarrhea disease in Northwestern Nigeria. Ann Afr Med. 2007;6(4):168-73.

20. Andreasi MS, Cardoso DD, Fernandes SM, Tozetti IA, Borges AM, Fiaccadori FS, et al. Adenovirus, calicivirus and astrovirus detection in fecal samples of hospitalized children with acute gastroenteritis from Campo Grande, MS, Brazil. Mem Inst Oswaldo Cruz. 2008;103(7):741-4.

21. Lee JI, Chung JY, Han TH, Song MO, Hwang ES. Detection of human bocavirus in children hospitalized because of acute gastroenteritis. J Infect Dis. 2007;196(7):994-7.

22. Savadkoohi RB, Ahmadpour-Kacho M, Yahyapour Y. Prevalence of viral gastroenteritis in children with acute gastroenteritis in Babol, Iran. J Pediatr Infect Dis. 2007;2(4):211-4.

23. Giordano MO, Ferreyra LJ, Isa MB, Martinez LC, Yudowsky SI, Nates SV. The epidemiology of acute viral gastroenteritis in hospitalized children in Cordoba City, Argentina: an insight of disease burden. Rev Inst Med Trop Sao Paulo. 2001;43(4):193-7.

24. Modares Shahezad RAA, Modares S, Faghihzadeh S, Jamafzon F, Karimi M. The role of Rotavirus in acute gastroenteritis and molecular epidemiology pattern of Rotavirus infection in hospitalized children in Tehran. Iranian Journal of Infectious Diseases and Tropical Medicine. 2005

25. Zarnani AH, Modarres S, Jadali F, Sabahi F, Moazzeni SM, Vazirian F. Role of rotaviruses in children with acute diarrhea in Tehran, Iran. J Clin Virol. 2004;29(3):189-93.

26. Bresee J, Fang ZY, Wang B, Nelson EA, Tam J, Soenarto Y, et al. First report from the Asian Rotavirus Surveillance Network. Emerg Infect Dis. 2004;10(6):988-95. 